London, on March 17, Dr. Michael Grant, president and vice-chancellor of the Queen's University of Belfast, discussed particularly the extraordinarily increasing activity and problem of making specialized knowledge available to the non-specialized adult public, and especially - since his subject was the diffusion of knowledge- of the printed word rather than the use of television or sound-radio ( $\mathrm{Pp}, 15$. London : Goldsmiths' College, 1960). The amount of actual knowledge imprinted on the adult general public by these media remains infinitesimal in comparison with what is gathered from printed books ; and Dr. Grant directed attention to the fact that commercial advertisers still spend only 13 per cent of their funds on television and 47 per cent on the Press. The sale of informative paper-backed books, of which first editions of as many as 50,000 might bo printed and sold, was further evidence of the existence of a demand for popular knowledge.

Discussing the problems involved in popularizs. tion, Dr. Grant referred to the difficulty of simplification but emphasized that good popularization could creato the atmosphere for good scholarship, in which before long important new research could arise: diffusion and stimulus could go together. There were also problems of vocabulary and presentation as well as of scholarship, nor was it possible to ignore entirely pronouncements on moral or even social values. Even a smattering of reasonably accurate knowledge, however, would make the nonspecialized adult population much loss likely to become credulous victims of all the nonsense of which people try to convince them, and the spreading of knowledge by popularization was highly relevant to the problem summed up by Sir Charles Snow as that of the two cultures. That problem could not be loft entirely to the universities, though he thought they should study deliberately how to produco the habit of mind which will make its students want, both before and after graduation, to take an openminded interest in at least something worth while outside their own careers. In conclusion, he appealed to his hearers generally to participate themselves in this extremely difficult, heavily criticized but fascinating task of popularizing knowledgo, which was worth doing and had to be done, and was more likely to be done successfully by teachers than by most other people.

\section{New C.S.I.R.O. Sugar Research Laboratory}

IT is announced that a new Sugar Research Laboratory will be set up by the Commonwealth Scientific and Industrial Research Organization, to form part of the Organization's Chemical Research Laboratories in Melbourne. The decision to establish the Labor. atory has come after considerable discussion with representatives of the sugar industry, which is anxious to find new uses for the present surplus in Australian production. The surplus corresponds to about a million tons of sugar cane per year. Australia's biggest sugar producer, the Colonial Sugar Refining Co., Ltd., has agreed to contribute $£ 2,500$ per annum towards tho running costs of the Laboratory. Dr. H. H. Hait, previously officer-in-charge of the Organization's Organic Chemistry Section, has been appointed leader of research in the new unit.

The Output of Scientists in Scotland : 1600-1950

IN a paper, "The Ontput of Scientists in Scotland, 1600-1950", published in The Eugenics Review,
July 1960 , R. H. S. Robertson advances evidence that from the beginning of the seventeenth until the middle of the eighteenth century the proportion of scientists born in Scotland who emigrated steadily increased : from then until about 1825 it tended to decrease, and in that year 71 per cent of the scientists selected for his sample died in Scotland, compared with 48 per cent in 1750 . From 1825 , however, the proportion of scientifically gifted Scots who emigrated has increased at an alarming rate, in spite of a slight evening off in the curve and even a recovery in recent years. Since a high proportion of the net loss of emigrants from Scotland of about 24,000 a year is from the more intelligent classes, Robertson urges that action is imperative if disaster is to be prevented. Scotland, he claims, produces 20 per cent of the British output of scientists and technologists, but only some 3 per cent of British scientific posts are available within her boundaries. Attributing the decline in the number of Scottish posts chiefly to the unequal distribution in Britain of research institutions, ho urges that research institutes and posts in Scotland should be increased to about 10 per cent of the British total.

Museum of Applied Science of Victoria, Melbourne

THE annual report for 1958-59 of the Museum of Applied Science of Victoria, Melbourne, records the welcome news that tenders have been accepted for building extensions and that it is hoped to complete the work by the end of 1960 . As available space will be increased by about 50 per cent, this will be the greatest expansion of the Museum since its foundation in 1870 (Pp. 30. Melbourne: Museum of Applied Science of Victoria, 1960). Major displays include exhibitions celobrating one hundred years of Stateoperated railways in Victoria, present-day telephones, and a sectioned model of a reactor. The increasing interest in space exploration and uppor atmosphere research led to the instellation of a working exhibit showing satellites in orbit around the Earth. A working exhibit was also made to demonstrate the bchaviour of a low-voltage halogen-quenched Geiger tube and its use for radiation measurement. The circuit includes a counting-rate meter for visual monitoring and a loud-speaker for aural monitoring.

\section{Indexes for Scientific and Technical Reports}

AN investigation by the Research Department of the Association of Special Libraries and Information Bureaux into the indexing of published reports of scientific and technical conferences and symposia, prompted by an inquiry which cited some examples of unindexed publications of this type, established that half the published proceedings and reports of such conferences are provided with neither subject nor author indexes. Based on a survey of some 205 such publications noted in the British National Bibliography during January 1956-September 1959, inclusive, the survey showed that 59 per cent were without subject indexes and 66 por cont without author indexes, 50 per cent being without both. Publications of 301-400 pages were best provided with subject indexes ( 66 per cent), whereas 90 per cent of those of up to 100 pages were without, 71 per cent of those with 101-200 pages, 57 per cent of those with 201-300 pages, 54 per cent of those with 401-500 pages and 50 per cent of those with more than 500 pages. The position appears to be worsening, the perentage of publications without subject indexes in 1956 being 47 ; in 1957,$60 ; 1958,61$; and in 